\title{
Characterization of Insecticide Cross-resistance in a Fenitrothion- resistant Strain of Culex pipiens Larvae
}

Korrat, R.A.A. ${ }^{\text {; Y.A. Ibrahim }}{ }^{2}$; A.M. El-Ghareeb ${ }^{2}$ and S.A. Ahmed ${ }^{1}$

${ }^{1}$ Department of Plant Protection, Faculty of Agriculture, Al-Azhar University.

${ }^{2}$ Department of Plant Protection, Faculty of Agriculture, Assiut University.

Received on: $28 / 1 / 2016$

Accepted for publication on: 15/2/2016

\begin{abstract}
Insecticide resistant strains of mosquitoes is considered as a main problem in controlling malaria and dengue diseases. In the present study, a fenitrothion resistant strain (FEN-R-strain) of Culex pipiens larvae in Assiut University, Assiut Egypt, proved to have a high level of cross-resistance against the organophosphate insecticides. Cross-resistance to malathion $\left(\mathrm{RR}_{50}=634\right.$.86-fold $)$ was higher than that of fenitrothion $\left(\mathrm{RR}_{50}=426.70\right.$-fold), whereas the crossresistance to diazinon $\left(R_{50}=97.86\right.$-fold $)$ was lower than that of fenitrothion. $\mathrm{RR}_{50}$ on the other hand, the resistant strain had low level of cross-resistance toward chlorpyrifos $\left(\mathrm{RR}_{50}\right.$ were 31.8-fold) as compared with the other tested organophosphates. The results revealed that larvae of FEN-R-strain displayed slightly high cross-resistance to the pyrethroid insecticide deltamthrin $\left(\mathrm{RR}_{50}=22.32\right.$ fold), moderate cross-resistance to cypermthrin $\left(\mathrm{RR}_{50}=16.90\right.$-fold $)$ and permethrin $\left(R_{50}=12.64\right.$-fold $)$ and lless cross-resistance level was to fenvalerate $\left(R_{50}=\right.$ 1.67-fold). Larvae of FEN-R-strain displayed high cross-resistance to the carbamate insecticide propoxure $\left(\mathrm{RR}_{50}=10.18\right.$-fold $)$, low cross-resistance or tolerance to carbaryl $\left(\mathrm{RR}_{50}=4.13\right.$-fold $)$ and very low cross-resistance or tolerance to methomyl $\left(\mathrm{RR}_{50}=1.96\right.$-fold). Data also indicated that larvae of the FEN-R-strain of Culex pipiens displayed slight cross-resistance to the bioinsecticide spinosad $\left(\mathrm{RR}_{50}=250.53\right.$-fold $)$ and low cross-resistance or tolerance to avermectin $\left(\mathrm{RR}_{50}=\right.$ 8.52-fold). Larvae of FEN-R-strain showed moderate cross-resistance or tolerance to the insect growth inhibitor insecticide pyriproxyfen $\left(R_{50}=10.30\right.$-fold $)$.

The variability in cross-resistance values in larvae of FEN-R-strain of $C x$. pipiens to different conventional insecticides seem to indicate the absence of single mechanism controlling resistance among and within the insecticides classes (organophosphate, pyrethroide, carbamate, bioinsecticide and IGR insecticides). This pattern suggests multiple mechanisms of resistance, i.e. metabolic resistance and insensitive target site.
\end{abstract}

Keywords: Insecticide resistant, Cross-resistance, Mosquito, Culex pipiens, Fenitrothion.

\section{Introduction}

The common and widely distributed mosquitoes across Egypt, $\mathrm{Cu}-$ lex pipiens (Linnaeus) has been incriminated as the main vector of bancroftian filariasis (Southgate, 1979), and Japanese encephalitis. Over 120 million people from 83 countries are physically disabled by lymphatic filariasis caused by Culex mosquitoes (WHO, 1995). For the last 50 years, pesticides have been widely used to control mosquitoes. In 1989, among the 504 arthropod species that had 
become resistant to one or more insecticide families, 114 were mosquitoe species, the most important vector of human diseases (Georghiou and Lagunes-Tejeda 1991). A limited resistance mechanisms, including modification of target site, or changes in rate of metabolism involving esterases, glutathione S-transferases or monooxygenases operate in all insects. The development of resistance has been apparent since the 1950's, but the scale of the problem has been poorly documented. Few new public health insecticides have been developed for controlling of disease vectors for the past three decades without good stewardship. These insecticides will cease to be effective for vector control. This may have a dramatic effect in disease endemic countries, as few affordable alternative insecticides can rapidly be made available for vector control. The ability to optimally measure and manage insecticide resistance in field populations of insects is crucial to the long term sustainability of insecticide-based disease control campaigns by (Coleman and Hemingway, 2007). The objective of this study have investigate resistance pattern of a fenitrothion resistant strain (FEN-R-strain) of Cx. pipiens larvae.

\section{Materials and Methods}

\section{Insecticides}

The toxicants used in the present experiments belonged to organophosphates, the synthetic pyrethrioids, carbamates, bioinsecticides and IGR compounds. Organophosphorus compounds were: Chlorpyrifos; Dursban (48\% E.C) (Dow Chemical CO.), Diazinon; Diazin $(5 \%$ G) (K.Z. CO.), Fenitrothion
; Sumithion (50\% E.C) (Sumitomo Chemical CO.) and Malathion; Agrothion (57\% E.C) (Agro Chemical CO.). Carbamate compounds were: Carbaryl ; Sevin (1\% Dust) (K.Z. CO.), Methomyl ; Lannate (90\% W.S.P) (Dobon di numorz CO.USA) and Propoxur Technical grade. (Sumitomo Chemical CO.).

Pyrethroid compounds were: Cypermethrin; Ripcord (10\% E.C) (Shell international Chemical CO.), Deltamethrin; K-othrin (2.5\% W.p) (K.Z. CO.), Fenvalerate ; Sumicidin $(20 \%$ E.C) (Sumitomo Chemical CO.) and Permethrin, Technical grade. (Sumitomo Chemical CO.), Bioinsecticide compounds were: Abamectin; Vertemic (1.8\% E.C) (Syngenta. CO.) and Spinosad; Spinotor (24\% S.C) (Dow Agro Chemical CO.) and IGR compound was: Pyriproxyfen; Admiral (10\% E.C) (Sumitomo Chemical CO.).

\section{2- Chemicals Used as surfactants}

TritonX100 (100\% purity, BDH Chem, Ltd. Poole England)

\section{3- Insect strains}

Two strains of $C x$. pipiens were used in this study as follows: strain)

A- Susceptible strain (S-

The susceptible strain used in the present study was brought from the Institute of Veterinary and Medical Insects in Cairo, which reared in the lab for 5 years away from any insecticidal pressure.

\section{B-Resistant strain fenitrothion} (FEN-R-strain)

This strain was obtained by selecting a part of the parent field strain (which was collected in season of abundance, from Faculty of Agriculture Farm, Assiut, University, Assiut Go- 
vernorate.) $\left(\sim 100004^{\text {th }}\right.$ instar larvae $)$ with the OP insecticide fenitrothion. Selection pressure was carried out by dipping the $4^{\text {th }}$ instar larvae for fifteen successive generations at the $\mathrm{LC}_{50}$ level of each generation.

\section{4- Collecting and rearing tech- niques}

All strains transferred to laboratory of Plant Protection Department, Fac. Agric., Assuit University and reared under laboratory conditions of $25 \pm 2 \mathrm{C}^{\circ}$ and $60 \pm 5 \%$ R.H. throughout the study. Mosquito (S-strain, fenitrothion resistant strain) rearing was maintained in enamel trays. Transformed pupae were collected from the aforementioned trays by means of a wide mouth glass dropper, then pipette into Petri dishes that were placed in the adult cages $(30 \mathrm{~cm}$ dimensions). The emerging males were fed on $10 \%$ sucrose solution and females were fed on pigeon breast blood meat, respectively. Suitable containers for egg-laying were provided to the cages 48 hours after adult emergence and female feeding for egg-laying. Receptacles containing egg rafts were daily collected from the cages, then the newly hatched larvae were then transferred to the breading trays, each containing 2 inch high tap water and provided with 500 larvae of the same age. After twenty four hours, the hatched larvae were fed on fresh yeast and protein which was evenly sprinkled on the water surface twice daily. The left over yeast, that was not ingested, was carefully removed with a medicinal dropper. Mass-rearing colony of all stages was maintained at $25 \pm 2 \mathrm{C}^{\circ}$ and $60 \pm 5 \%$ R.H. Temperature and relative humidity readings were daily measured using a thermograph and hydrograph, respectively.

\section{5- Bioassay tests}

\section{A- Toxicity studies}

Sensitivity of investigated strains (S-strain and FEN-R-strains) of $C x$. pipiens to the tested insecticides was checked in accordance with procedure described by the WHO (1981). The $4^{\text {th }}$ instar larvae were used in the course of the present study. To the beakers, which were used for testing the insecticides a volume of $225 \mathrm{ml}$ of tap water was added. Then $0.5 \mathrm{ml}$ of different concentrations, in acetone, of each insecticide plus Triton $\mathrm{X}_{100}$ was separately added to those beakers. The final concentration of Triton $\mathrm{X}_{100}$ was 10 $\mathrm{ppb}$. The serial concentrations of each insecticide tested were sufficient to cover almost a complete range of mortality. Three replicates per each concentration were used and each replicate contain $204^{\text {th }}$ instar larvae. Mortality was recorded $24 \mathrm{~h}$ after treatment. Control was made with 0.5 $\mathrm{ml}$ acetone plus Triton $\mathrm{X}_{100}$. Temperature was maintained at $27 \pm 1 \mathrm{C}^{\mathrm{o}}$ during bioassay. The mortality percentages were corrected using Abbot's formula (1925). Concentration- mortality regression lines were analyzed using a computer program modified from the method of Finney (1971) to estimate the $\mathrm{LC}_{50}$, the confidence limits and slopes of LCp lines.

\section{B- Cross-resistance studies}

The cross-resistance value for each tested insecticide was calculated as:

$\mathrm{LC}_{50}$ value of resistant strain (FEN-R-strain)/ $\mathrm{LC}_{50}$ value of susceptible strain (S-strain).

\section{Results and Discussion}


To investigate the crossresistance spectrum in FEN-R-strain (426.7-fold resistance to fenitrothion) of Cx. Pipiens larvae, the toxicity of thirteen insecticides including organophosphates (chlorpyrifos, diazinon and malathion), pyrithroids (cypermthrin, deltamthrin, fenvalerate and permethrin), carbamates (carbaryl, methomyl and propoxur) bioinsecticids (avermectin and spinosad) and the insect growth inhibitor pyriproxyfen were tested against 4th instar larvae of FEN-R-strain and S-strain. Resistance ratios (RR50) were calculated by dividing the LC50 of the FEN-R-strain by the LC50 value of the S-strain for the same insecticide. The data presented in Table 1 and Figures 1 and 2. Resultus indicate that the FEN-R-strain of Cx. pipiens larvae exhibited different levels of cross-resistance to the tested organophosphates insecticides, the crossresistance could be ranked in descending order of resistance ratio (RR50) as follow: malathion (634.86fold), diazinon (97.86-fold) and chlorpyrifos (31.8-fold). The crossresistance to the tested pyrithroid insecticdes could be ranked in descending order: deltamthrin (22.32-fold), cypermthrin (16.0-fold), permethrin (12.64-fold) and fenvalerate (1.67fold). Carbamate insecticides could be ranked as follow: propoxur (10.18fold), carbaryl (4.13-fold) and methomyl (1.96-fold). Bioinsecticides could be ranked as follow: spinosad (250.53-fold) and avermectin (8.52fold). The cross-resistance to the tested insect growth inhibitor insecticide pyriproxyfen was 10.30-fold.

Table 1. Toxicity and cross resistance of certain insecticides against the $4^{\text {th }}$ instar larvae of the fenitrothion selected strain (FEN-R-strain) and the susceptible strain (S-strain) of Cx. pipiens.

\begin{tabular}{|c|c|c|c|c|c|c|c|}
\hline \multirow[b]{2}{*}{$\mathbf{S}$} & \multirow{3}{*}{ Insecticides } & \multirow{3}{*}{$\begin{array}{c}\text { S-strain } \\
\mathrm{LC}_{50} \\
\mu \mathrm{g} / \mathrm{L}\end{array}$} & \multicolumn{5}{|c|}{ FEN-R-strain } \\
\hline & & & \multirow{2}{*}{$\begin{array}{l}\mathrm{LC}_{50} \\
\mu \mathrm{g} / \mathrm{L}\end{array}$} & \multicolumn{2}{|c|}{ C. Limits $95 \%$} & \multirow{2}{*}{ Slope \pm S.E } & $\mathbf{R R}^{(\mathbf{a})}$ \\
\hline \multicolumn{4}{|c|}{ Organophosphorus } & & & & \\
\hline $\mathbf{1}$ & Fenitrothion & 0.720 & 307.227 & 229.012 & 381.436 & $3.70 \pm 0.85$ & 426.71 \\
\hline 2 & Chlorpyrifos & 0.601 & 19.222 & 12.836 & 25.280 & $1.91 \pm 0.35$ & 31.98 \\
\hline 3 & Diazinon & 0.427 & 41.789 & 30.259 & 52.719 & $2.10 \pm 0.45$ & 97.86 \\
\hline 4 & Malathion & 0.116 & 73.644 & 60.237 & 91.375 & $2.35 \pm 0.38$ & 634.86 \\
\hline \multicolumn{8}{|c|}{ Pyrthroides } \\
\hline 5 & Cypermthrin & 0.103 & 1.741 & 1.374 & 2.279 & $2.19 \pm 0.33$ & 16.90 \\
\hline 6 & Deltamthrin & 0.266 & 5.938 & 5.434 & 6.498 & $5.94 \pm 1.10$ & 22.32 \\
\hline 7 & Fenvalerate & 0.334 & 0.558 & 0.510 & 0.605 & $6.31 \pm 1.11$ & 1.67 \\
\hline 8 & Permethrin & 0.367 & 4.640 & 4.171 & 5.113 & $5.29 \pm 0.92$ & 12.64 \\
\hline \multicolumn{8}{|c|}{ Carbamates } \\
\hline 9 & Carbaryl & 0.380 & 1.571 & 1.306 & 1.974 & $2.77 \pm 0.45$ & 4.13 \\
\hline 10 & Methomyl & 5.869 & 11.516 & 9.556 & 13.912 & $2.93 \pm 0.46$ & 1.96 \\
\hline 11 & Propoxur & 1.730 & 17.611 & 13.080 & 21.563 & $2.60 \pm 0.47$ & 10.18 \\
\hline \multicolumn{8}{|c|}{ Bioinsecticides } \\
\hline 12 & Aver & 0.257 & 2.190 & 1.747 & 2.625 & $2.79 \pm 0.48$ & 8.52 \\
\hline 13 & Spinosad & 0.017 & 4.259 & 3.849 & 4.630 & $6.29 \pm 0.97$ & 250.53 \\
\hline \multicolumn{8}{|c|}{ Insect growth inhibitor } \\
\hline 14 & Pyriproxyfen & 0.033 & 0.340 & 0.289 & 0.389 & $3.70 \pm 0.69$ & 10.30 \\
\hline
\end{tabular}

(a) RR: Cross resistance $=\mathrm{LC}_{50}$ of the tested insecticide in FEN-R strain $/ \mathrm{LC}_{50}$ of the same insecticide against $\mathrm{S}$-strain. 


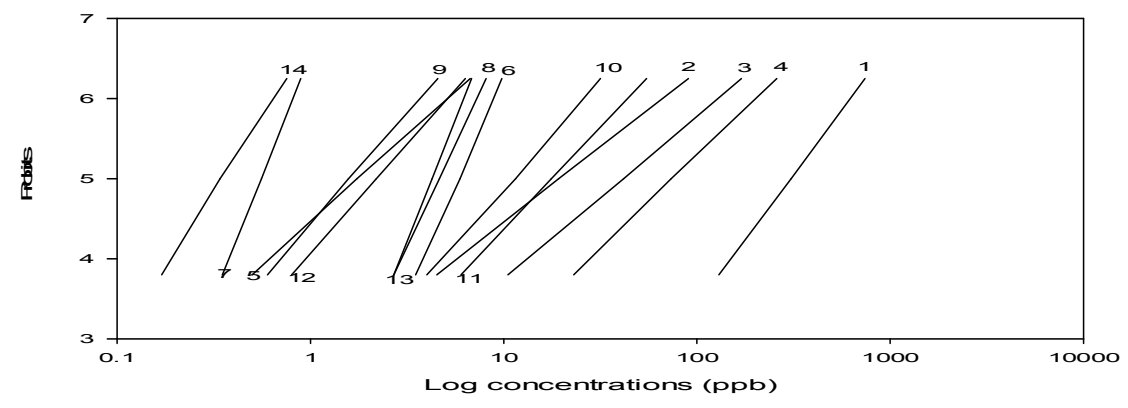

Fig. 1: Relationship between probit equivalent to percentages of mortality and log cocentrations $(\mu \mathrm{g} / \mathrm{L})$ of (1) fenitrothion, (2) chlorpyrifos, (3) diazinon, (4) malathion, (5) cypermthrin, (6) deltamethrin, (7) fenvalerate, (8) permethrin, (9) carbaryl, (10) methomyl, (11) propoxur, (12) avermectin, (13) spinosad, and (14) pyriproxyfen applied to $4^{\text {th }}$ instar larvae of fenitrothion. resistant strain (FEN-R-strain) of $C x$. pipiens

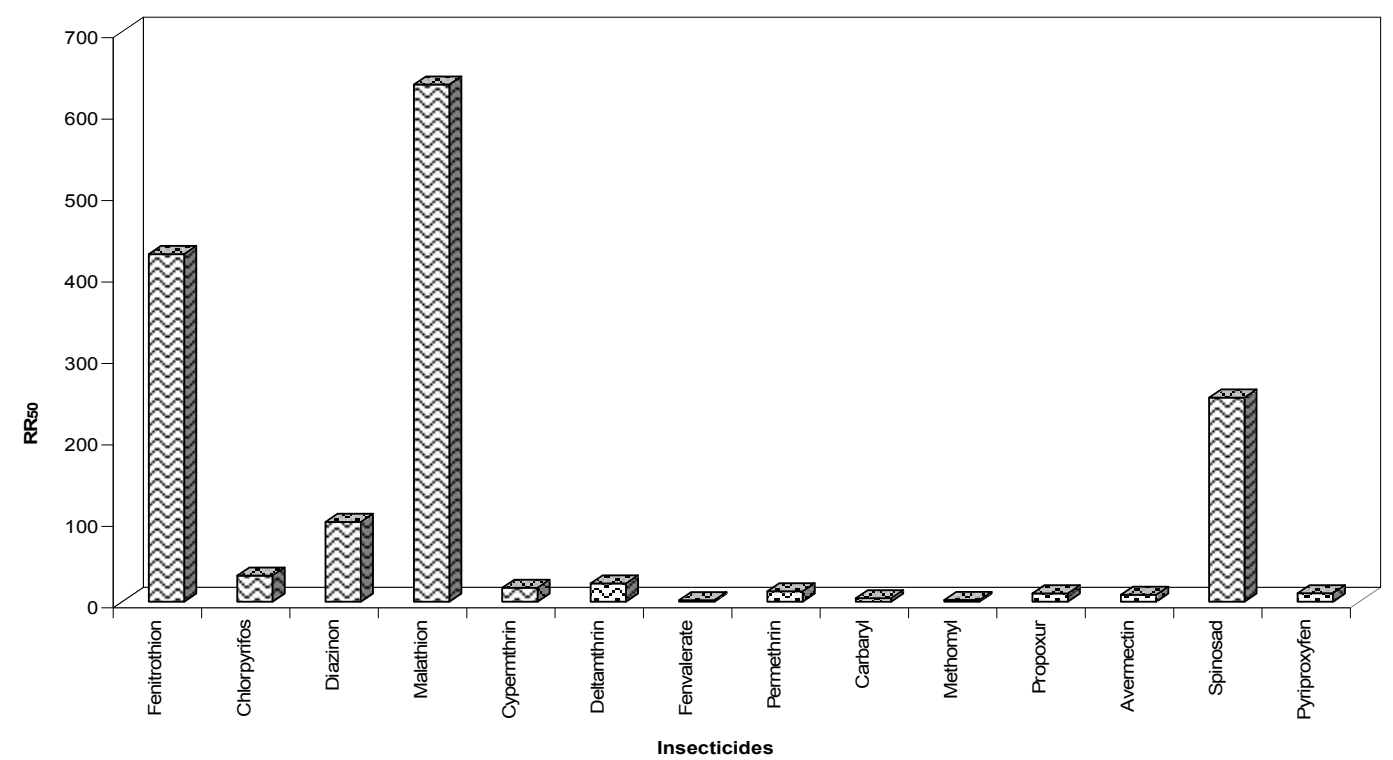

Fig. 2: Resistance ratio $\left(\mathrm{RR}_{50}\right)$ of certain insecticides in fenitrothion resistant strain (FEN-Rstrain) in relation to the susceptible strain (S-strain) of $C x$. pipiens larvae.

Valles et al. (1997), Kerns and Gaylor (1992) and Liu et al. (2004) suggested that an insect strain with resistance ratio $\left(R_{50}\right)$ value of $<10$ is considered tolerant, while that with $\mathrm{RR}_{50}$ value of $10-20$ is moderately resistant and that with $R_{50}$ value of $>20$ is highly resistant. This classification was taken into consideration with the tested insecticides in the present study.
From the above mentioned results, the FEN-R-strain proved to have a very high degree of crossresistance to all the tested organophosphates but in different levels. Cross-resistance to malathion $\left(\mathrm{RR}_{50}=\right.$ 634.86-fold) was higher than of fenitrothion $\left(\mathrm{RR}_{50}=426.70\right.$-fold $)$, whereas the cross-resistance to diazinon $\left(\mathrm{RR}_{50}=97.86\right.$-fold $)$ was lower than the $\mathrm{RR}_{50}$ of fenitrothion. On the other hand, the resistant strain had an even 
lower degree of cross-resistance toward chlorpyrifos $\left(\mathrm{RR}_{50}\right.$ were 31.8fold) as compared with other tested organophosphates. The high crossresistance to organophosphates seem to be conform with the hypothesis that cross-resistance was highly observed when the toxicant is chemically similar to the one used in the selection. This is expected as similar insecticidal structure indicates a likely common mechanism(s) of action and detoxification Bracco et al. (1999).

Hidayati et al. (2011) stated that the level of resistance to fenitrothion in Ae. Aegypti may result from continuous exposure to the selection pressure with malathion which is the same insecticide class. The results that the mosquitoes are more resistant to fenitrothion compared to malathion are similar to the study of Bracco et al. (1999). Corena et al. (2002) reported that the increase in resistance to temephos over six generations was associated with an increase in resistance to some other organophosphorus insecticides (fenitrothion, fenthion and malathion).

Table 1 and Figures 1 and 2 revealed that larvae of the FEN-Rstrain displayed relatively high crossresistance to the pyrethroid insecticide deltamthrin $\left(\mathrm{RR}_{50}=22.32\right.$-fold $)$ moderate cross-resistance to cypermthrin $\left(\mathrm{RR}_{50}=16.90\right.$-fold $)$ and permthrin $\left(\mathrm{RR}_{50}=12.64\right.$-fold $)$ and less cross-resistance was to fenvalerate $\left(\mathrm{RR}_{50}=1.67\right.$-fold $)$. As expected, cross-resistance to insecticides structurally unrelated to the selecting OPinsecticide (fenitrothion) was far less than that of other OP-insecticides. This finding supports the use of insecticides structurally unrelated to overcome the phenomenon of crossresistance in Cx. pipiens larvae.

This result is in agree with Corena et al. (2002) who found significant increase in resistance to deltamethrin with temephos selection. A surprisingly relative high increase in resistance was detected to deltamethrin (71.05-fold), low level of resistance was detected with cyfluthrin (5.76-fold) and cypermethrin (1.80fold).

Table 1 and Figures 1 and 2 revealed that larvae of the FEN-Rstrain displayed relative high crossresistance to the carbamate insecticide propoxure $\left(\mathrm{RR}_{50}=10.18\right.$-fold), low cross-resistance or tolerance to carbaryl $\left(\mathrm{RR}_{50}=4.13\right.$-fold $)$ and very low tolerance to methomyl $\left(\mathrm{RR}_{50}=\right.$ 1.96-fold). Usually, when a resistant strain is selected with an insecticide, resistance extends to other compounds of the same class of insecticides or to compounds with similar modes of action (Liu et al., 2004).

Larvae of the FEN-R-strain displayed relatively high crossresistance to the bioinsecticide spinosad $\left(\mathrm{RR}_{50}=250.53\right.$-fold $)$ and low cross-resistance or tolerance to avermectin $\left(\mathrm{RR}_{50}=8.52\right.$-fold $)$. The level of resistance toward spinosad in FEN-R-strain in the present study was not in agreement with those reported by several investigaors. In their review on spinosad, as natural product for larval mosquito control, Hertlein et al. (2010) reported that spinosad acts on the postsynaptic nicotinic acetylcholine and GABA receptors of insects and has been demonstrsted to possess a unique mode of action not shared by any other known insecticidal class of chemistry 
(Salgado and Sparks, 2005). According to Valles et al., 1997, it was revealed that lower susceptibility of 7fold to abamectin in the field strain is considered tolerant rather than resistant. The present results indicate that the mechanism(s) responsible for high level of resistance against organophosphates confers no crossresistance to abamectin.

Larvae of the FEN-R-strain displayed relative low tolerance to the insect growth inhibitor insecticide pyriproxyfen $\left(\mathrm{RR}_{50}=10.30\right.$-fold). Resistance to the IGR insecticide, pyriproxyfen in larval stage of field populations representing certain Culex, Aedes and Anopheles mosquito species were investigated. The obtained data by Selim (2001) revealed that the $\mathrm{LC}_{50}$ value for pyriproxyfen to $4^{\text {th }}$ instar larvae of a field strain of $C x$. pipiens was $0.0091 \mu \mathrm{g} / \mathrm{ml}$ compared with $0.0009 \mu \mathrm{g} / \mathrm{ml}$ for susceptible strain, indicating that the field strain exhibited 10.11-fold resistance to pyriproxyfen.

From the abovementioned results, the FEN-R-strain of $C x$. pipiens larvae proved to have degree of cross-resistance to all the tested insecticides but in different levels. For example, with respect to the tested OP-insecticides, the FEN-R-strain had high level of cross-resistance toward malathion $\left(\mathrm{RR}_{50}=634.86\right.$-fold $)$ whereas $R R_{50}$ value was only 31.98 fold to chlorpyifos Among the carbamate insecticides, the FEN-R-strain exhibited high level of crossresistance against propoxure $\left(\mathrm{RR}_{50}=\right.$ 10.18-fold), whereas $R_{50}$ value was only 1.96 -fold to methomyl. Interestingly, the FEN-R-strain proved to have high level of cross-resistance to deltamethrin $\left(\mathrm{RR}_{50}=22.32\right.$-fold $)$, whereas the $\mathrm{RR}_{50}$ values for fenvalerate was less than 1.67-fold. Generally, among the tested anticholinesterase insecticides, cross-resistance levels to OP insecticides were higher than those of carbamate insecticides in the tested FEN-R-strain. However it exhibited high level of crossresistance toward the tested anticholinesterases compared with the tested pyrethroid insecticides. Moreover the FEN-R-strain exhibited high level of cross-resistance toward the bioinsecticide spinosad $\left(\mathrm{RR}_{50}=250.53\right.$-fold $)$, whereas the $\mathrm{RR}_{50}$ values for avermectin were less than 8.52-fold.

The variability in crossresistance values in larvae of the FEN-R-strain of $C x$. pipiens larvae to different conventional insecticides seem to indicate the absence of a single mechanism controlling resistance among and within the insecticides classes (OPs, pyrethroides, carbamates, bioinsecticides and IGR insecticide). This pattern suggests multiple mechanisms of resistance, i.e. metabolic resistance and insensitive target site. Diverse resistance mechanisms have already been identified in several strains of field collected mosquitoes (Weill et al., 2003 and Liu et al., 2005). Multiple mechanisms acting in concert seem to be common phenomena in insecticide resistance of mosquitoes (Brengues et al., 2003 and Liu et al., 2005). Interactions of these mechanisms obviously results in increasing level of cross-resistance.

\section{References}

Abbott, W.A. (1925). A method of computing the effectiveness of an insecticide. J. Econ. Entomol. 18: 265-267. 
Bracco, T.E.; Barata, J.M.S. and Marinotti, O. (1999). Evaluation of insecticide resistance and biochemical mechanisms in a population of Culex quinquefasciatus (Diptera: Culicidae) from Saw paulo, Brazil. Memorias do Instituto os Waldo Cruz 44, 1:115-120.

Brengues, C.; Hawkes, N.J.; Chandre, F.; McCarroll, L.; Duchon, S.; Guillet, P.; Manguin, S.; Morgan, J.C. and Hemingway, J. (2003). Pyrethroid and DDT cross-resistance in Aedes aegyp$t i$ is correlated with novel mutations in the voltage gated sodium channel gene. Med. Vet. Entomol. 17: 87-94.

Coleman, M. and Hemingway, J. (2007). Insecticide resistance monitoring and evaluation in disease transmitting mosquitoes. J. Pest. Scien. 32, 2: 69-76.

Corena, M. del P., Seron, T.J., Lehman, H.K., Ochrietor, J.D., Kohn, A., Tu, C. and Linser, P.J. (2002). Carbonic anhydrase in the midgut of larval Aedes aegypti: cloning, localization and inhibition. J. Exp. Biol. 205, 591-602.

Finney, D.J. (1971). Probit Analysis. ( $3^{\text {rd }}$ Edition ed.), Cambridge University Press, Cambridge.

Georghlou, G.P. and Lagunes-Tejeda A. (1991). The occurrence of resistance to pesticides in arthropods. An index of cases reported through 1989. Rome, Italy: FAO.

Hertlein, M.B., Mavrotas, C., Jousseaume, C., Lysandrou, M., Thompson, C.D., Jany, W., and Ritchie, S.A. (2010). A review of spinosad as a natural product for larval mosquito control. J Am Mosq Control Assoc 26: 67-87.

Hidayati, H., W.A. Nazni, H.L. Lee, M. Sofian-Azirun (2011). Insecticide resistance development in Aedes aegypti upon selection pressure with malathion. Tropical Biomedicine 28:425-437.

Kerns, D.L. and Gaylor, M.J. (1992). Insecticide resistance in field populations of the Cotton aphid (Homoptera: Aphididae). J. Econ. Eniomol. 85: 1-8.

Liu, H.; Cupp, E.W.; Guo, A. and Liu, N.N. (2004). Insecticide resistance in Alabama and Florida mosquito strains of Aedes albopicutas. J. Medical Entomol 41, 5: 946- 952.

Liu, H.; Xu, Q.A.; Zhanq, L. and Liu, N.N. (2005). Chlorpyrifos resistance in mosquito Culex quinquefasciatus. J. Medical Entomol., 42: 5, 815 - 820 .

Salgado, V.L. and Sparks, T.C. (2005). The spinosyns: chemistry, biochemistry, mode of action, and resistance. Comprehensive Molecular Insect Science, 6: 137-173.

Selim, M.T.M. (2001). Development and mechanism of resistance to some insecticides IV insect transmitting diseases. M.Sc. Thesis, Department of Plant Protection Faculty of Agriculture, Ain Shams University.

Southgate, B.A. (1979). Bancroftian filariasis in Egypt. Trop. Dis. Bull. 76: 1045-1063.

Valles, S.M.; Koehler, P.G. and Brenner, R.J. (1997). Antagonism of fipronil toxicity by 
piperonyl butoxide and S, S, Stributyl phosphorotrithioate in the German cockroach (Dictyoptera: Blattellidae). J. Econ. Entomol. 90: 1254-1258.

Weill, M.; Lutfalla, G.; Mogensen, K.; Chandre, F.; Berthomieu, A.; Berticat, C.; Pasteur, N.; Philips, A.; Fort, P. and Raymond, M. (2003). Insecticide re- sistance in mosquito vectors. Nature (Lond.) 423: 136-137.

WHO. (1981). Instruction for determining the susceptibility or resistance of mosquito larvae to insecticides. $\mathrm{WHO} / \mathrm{VBC} /$ 81.684 .

WHO. (1995). Bridging the Gaps World Health Report. Geneva, Switzerland. 
خصائص المقاومة المشتركة للمبيدات علي سلالة مقاومة للفينتروثيون من يرقات بعوض بهن الكيوليكس بيبنز

رضا السيد السيد كرات'، يحي عبد الحميد ابراهيمץ'، عبدالرؤف محمد الغريب`، شريف أبو القاسم أحمد'

$$
\begin{aligned}
& \text { ' قسم وقاية النبات - كلية الزر اعة - جامعة الأزهر - أسيوط أسمال }
\end{aligned}
$$

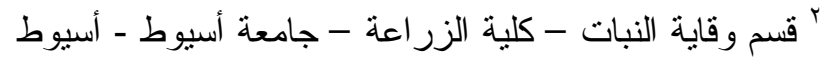

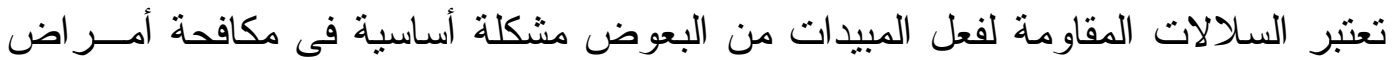

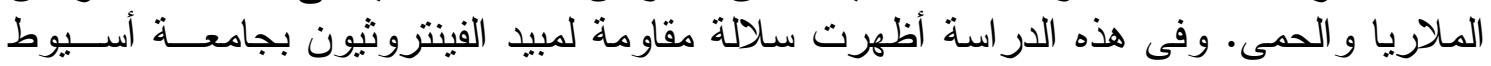

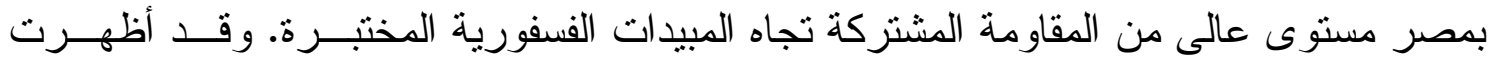

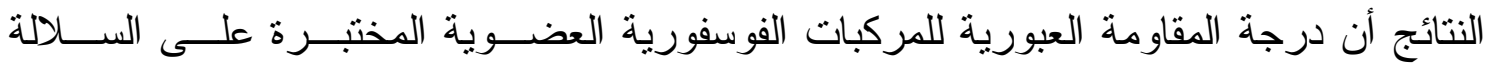

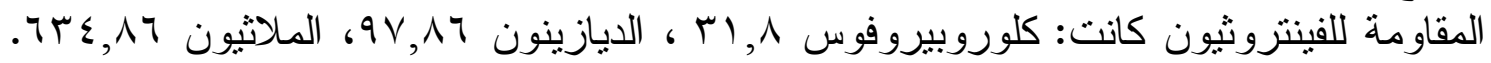

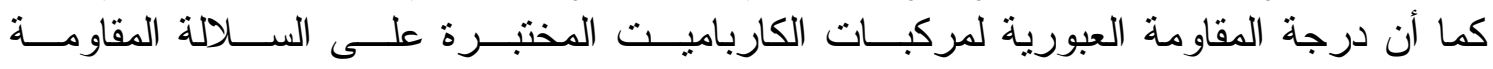

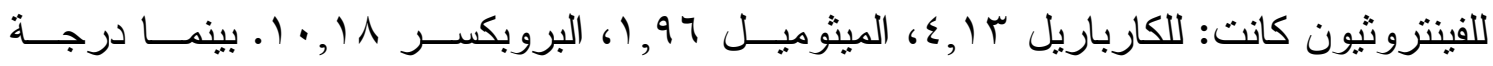

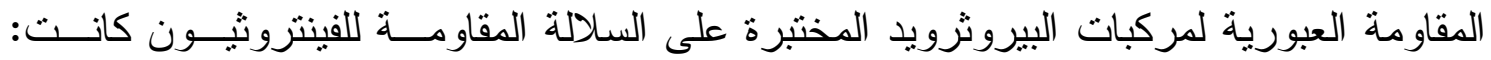

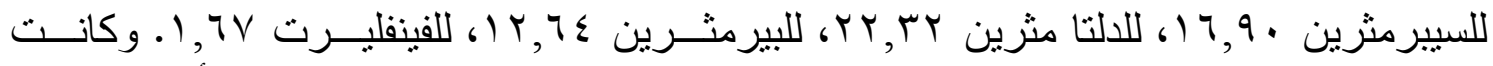

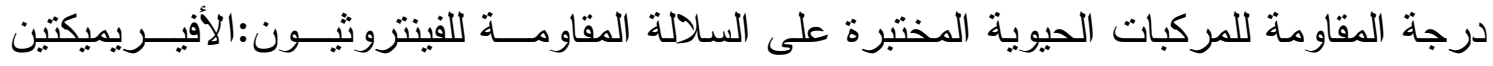

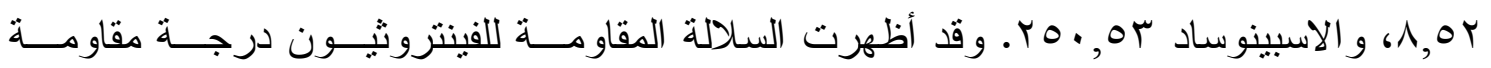
عبورية • r, • ا لمركب البيروبروكسفين (IGR) المختبر • ويمكن من النتائج السابقة القول بـــأن

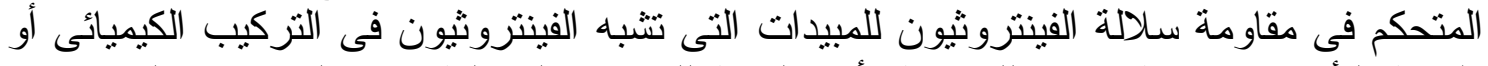

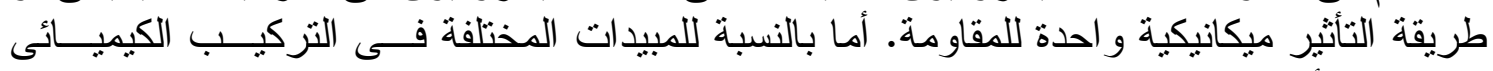

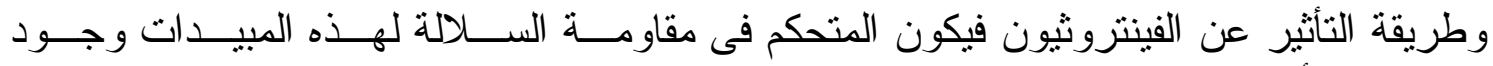
ميكانيكيات أخرى متعددة للمقاومة. 